\title{
USOS, SIGNIFICADOS E CONSERVAÇÃO DA PLANTA ESPADA DE SÃO JORGE, SANSEVIERIA ZEYLANICA, NA COMUNIDADE QUILOMBOLA BENEVIDES, AURORA DO PARÁ-PA-BRASIL.
}

\author{
USES, MEANINGS AND CONSERVATION OF THE SWORD PLANT OF SÃO \\ JORGE, SANSEVIERIA ZEYLANICA, IN THE QUILOMBOLA COMMUNITY \\ BENEVIDES, ARE AURORA OF PARÁ-PA-BRAZIL.
}

Adão Souza Borges ${ }^{1}$

\section{RESUMO}

Este artigo faz considerações sobre a relação da biodiversidade com os sujeitos amazônicos que protagonizam e resistem em prol do uso coletivo dos recursos naturais, quando a linguagem e os significados se enquadram em elementos de resistência, porque transitam no campo do sagrado. Busca compreender os usos, os significados e as formas de conservação da planta Espada de São Jorge (Sansevieria zeylanica) pelos quilombolas da comunidade Benevides, em Aurora do Pará, Brasil. O trabalho se desenvolveu de modo compreensivo nas análises de narrativas quilombolas sobre a planta Espada de São Jorge - sob o horizonte hermenêutico de Paul Ricoeur (1913-2005). Dentre os vários ciclos teóricos deduzíveis no conjunto bibliográfico de autoria do filósofo francês Paul Ricoeur, o aspecto teóricoreferencial deste trabalho privilegiou aquele presente na obra A Simbólica do Mal (RICOEUR, 2013). Assim, por uma hermenêutica simbólica de Ricoeur, a planta de poder Espada de São Jorge é analisada compreensivamente a partir de suas expressões no horizonte da linguagem comunitária, da imaginação poética, logo, no intercurso das narrativas cotidianas quilombolas.

Palavras-chave: Biodiversidade; Espada de São Jorge; Hermenêutica Ricoeuriana; Quilombolas; Símbolo.

\section{ABSTRACT:}

This article considers the relationship between biodiversity and the Amazonian subjects who lead and resist in favor of the collective use of natural resources, when language and meanings fit into elements of resistance, because they pass through the sacred field. It seeks to understand the uses, meanings and forms of conservation of the Espada de São Jorge (Sansevieria zeylanica) plant by quilombolas from the Benevides community, in Aurora do Pará, Brazil. The work was developed in a comprehensive way in the analysis of quilombola narratives about the Espada de São Jorge plant - under the hermeneutic horizon of Paul Ricoeur (1913-2005). Among the various theoretical cycles deductible in the bibliographic set by the French philosopher Paul Ricoeur, the theoretical-referential aspect of this work privileged that present in the work A Simbólica do Mal (RICOEUR, 2013). Thus, through

\footnotetext{
${ }^{1}$ Doutorando em Sociologia e Antropologia pela Universidade Federal do Pará, pelo Programa de PósGraduação em Sociologia e Antropologia (PPGSA). Atua como professor substituto da Universidade Federal do Pará (UFPA), Campus Bragança e exerce a função de professor (efetivo) da rede estadual de ensino da Secretaria de Educação do Governo do Estado do ParáE-mail: adaoaproaga@gmail.com
} 
Ricoeur's symbolic hermeneutics, the Espada de São Jorge power plant is comprehensively analyzed from its expressions in the horizon of community language, of poetic imagination, therefore, in the intercourse of quilombola daily narratives.

Keywords: Biodiversity; Espada de São Jorge; Ricoeurian Hermeneutics; Quilombolas; Symbol.

\section{INTRODUÇÃO}

No final do século XX e nas primeiras décadas do século XXI, o debate acerca da biodiversidade ainda é uma temática que não se esgota; ao contrário, continua necessário refletir acerca das questões que estão a ela atreladas, principalmente, no Brasil, hoje, quando as notícias denunciam as pressões sobre os recursos naturais e o uso exacerbado de agrotóxicos, que causam danos à vida humana, atestando um recrudescimento do Estado e o tornando impotente à proteção da vida.

Se estabeleceu na Amazônia um paradigma de socialização baseado no crescimento econômico, sem considerar os limites renováveis do bioma local (SIQUEIRA, 2020). Durante o governo militar, as políticas traçadas para a região amazônica favoreceram a implantação de empresas que desenvolveram projetos sob a égide da integração nacional e o avanço territorial do capital, como exploração de minérios, estradas e barragens, sem a preocupação com o ambiente. Vale frisar acerca dos incentivos fiscais concedidos a esses empreendimentos, por meio da Superintendência do Desenvolvimento da Amazônia (SUDAM), criada em 1966. A SUDAM atendeu, sobretudo, aos interesses do latifúndio e da exploração industrial-mineral, causa de grande impacto ao meio ambiente, como por exemplo os investimentos nas fazendas, que outrora cercam as comunidades quilombolas do entorno, da comunidade Benevides, que outrora tornaram-se empecilhos para a regularização fundiária das comunidades quilombolas na região.

Na década de 1980, intensificaram-se as pressões das agências financiadoras dos projetos de desenvolvimento, de um lado (Banco Mundial), e, de outro, houve pressão dos movimentos sociais, de onde o sindicalista Chico Mendes se tornou uma grande liderança, acompanhado da resistência de indígenas e de outros povos tradicionais. A promulgação da Constituição Federal de 1988 garantiu as demandas dessa população, transformando seus pleitos em políticas públicas, através da Comissão de Meio Ambiente, Minorias e Defesa do Consumidor, criação do Instituto Brasileiro do Meio Ambiente e Recursos Renováveis 
(IBAMA), e, sobretudo, criação das reservas extrativistas, o que garantiu os usos dos recursos naturais às populações tradicionais, que deles já faziam usufruto historicamente, através de suas apropriações culturais, como no caso das populações quilombolas, nas quais este artigo enfoca.

O ano de 1992 foi de grande valia para a biodiversidade, com a criação do Centro Nacional de Desenvolvimento Sustentado de Populações Tradicionais (CNPT), as unidades de conservação (UCs), além de ser realizada nesse período a ECO-92, que potencializou a afirmação da necessidade de criação de várias unidades de conservação, enquanto estratégia para a garantia da biodiversidade, encabeçada pelos movimentos sociais, que passaram a ser conhecidos como movimentos “ambientalistas”, a nível nacional e internacional.

Este trabalho é o resultado de pesquisas preliminares ressalta a importância que os povos tradicionais assumiram devido aos usos dos recursos naturais na Amazônia com menor impacto ambiental, bem como sua inclusão na gestão dos recursos naturais, propiciando a visibilidade dos seus saberes, que incluem as dimensões cultural, econômica e religiosa. Assim, podemos pensar na construção de um protagonismo desses sujeitos, em parceria com as instituições de pesquisa e pesquisadores, como é o caso dos remanescentes de quilombos, a Universidade Federal do Pará (UFPA), Museu Goeldi e pesquisadores, cujo pontapé inicial se deu com as cartografias feitas pelos quilombolas do Aproagra $^{2}$, pelo uso de suas memórias, para a identificação de usos de recursos coletivos.

Em 2009, a UFPA, por meio do Núcleo de Altos Estudos Amazônicos (NAEA), lançou o Atlas socioambiental: municípios de Tomé-Açú, Aurora do Pará, Ipixuna do Pará, Paragominas e Ulianópolis, que destaca a importância e as formas de relações de trabalho ocorridas nessa região no decorrer dos séculos XVIII e XIX, o que foi relevante por apresentar trabalhos inéditos sobre as populações locais do rio Capim. No final do ano de 2013, elaborava-se os Relatórios Antropológicos/INCRA com vistas à demarcação de terras das comunidades de Mariana/Viseu, de Rosário e Boa Vista, em Salvaterra (PA). Dessa maneira, podemos afirmar que esse Atlas contribui significativamente para a construção do conhecimento histórico e local e para o fortalecimento da identidade de comunidades, ocasionando a afirmação quilombola pelas comunidades, que buscaram na memória, nas

\footnotetext{
2 "O termo Aproaga ou Aproagra designa o engenho e, posteriormente à fazenda, situada à margem direita do rio Capim. As relações sociais com os que se declararam proprietários (Pedro Chermont de Miranda e herdeiros) do Aproaga vêm desde a escravidão até o presente" (ASSOCIAÇÃO QUILOMBOLAS UNIDOS DO RIO CAPIM, p. 3).
} 
lembranças de lugares, hábitos e costumes da reminiscência da ancestralidade. Parece, então, que a construção do passado no presente se dá em modo de uma representação identitária.

As comunidades Taperinha, Sauá Mirim e Nova Ipixuna atuaram no Projeto Nova Cartografia Social da Amazônia, série Movimentos sociais, identidade coletiva e conflitos, lançado em parceria com a Universidade Federal do Amazonas (UFAM), UFPA etc. Esta mobilização rendeu a formação da Associação Quilombolas Unidos do Rio Capim (AQURC). Esta institucionalização jurídica da associação aconteceu como reconhecimento da entidade cultural das comunidades. Pelas expressões das comunidades associadas foi possível a cartografia dos seus territórios e a garantia legal de seus bens (coletivos) naturais. Desta forma, segundo Borges (2014, p. 11), as tradições territoriais dos quilombolas ganharam reconhecimento público, logo, passaram a receber os direitos que lhes são garantidos nas esferas federais, estaduais e municipais.

Nesse sentido, o contato de remanescentes do Aproaga com essas instituições propiciou estudos sobre aquele povo, o que funcionou como incentivo para sua autoafirmação e pela pressão sobre o Estado pela legitimidade da terra. Outro efeito foi a dinamização da discussão sobre a identidade étnica desses povos e maior protagonismo de sua cultura, sua dinâmica econômica e, principalmente, a religiosidade que esses sujeitos manifestam ao usar as plantas medicinais, sobretudo aquelas que lhes põem em interação com o sagrado (BORGES, 2014).

O sagrado circunscrito na presença cultural da planta Espada de São Jorge acontece num sistema de crenças e toma dimensão sagrada à medida que ultrapassa seu princípio ativo. Sobre o sagrado religioso, afirma Durkheim

[...] aquilo que é característico do fenômeno religioso é que ele sempre supõe uma divisão bipartida do universo conhecido e cognoscível em dois gêneros que compreendem tudo aquilo que existe, mas que se excluem radicalmente. As coisas sagradas são aquelas que os interditos protegem e isolam; as coisas profanas, aquelas às quais os interditos se aplicam e que devem se manter distantes das primeiras. As crenças religiosas são representações que exprimem a natureza das coisas sagradas e as relações que elas possuem entre si e entre as coisas profanas. E os ritos são as regras de conduta que prescrevem como os homens devem se comportar com as coisas sagradas (DURKHEIM, 1968, p. 68).

Assim, a compreensão que permeia nosso texto é a de que as plantas tornam-se sagradas quando determinada sociedade não as enxerga apenas como vegetais, mas, como um elemento investido de poder, que é envolto a outro sistema, de prevenção/proteção e de cura. Nessa lógica, contrariando a ciência médica, fundamentada no paradigma da objetividade, discorrer acerta dessa temática significa transitar num campo que é amplo, portanto, subjetivo, 
interdisciplinar, que precisa ser refletido, vivido e produzido com sujeitos produtores de cultura, de saberes, de crenças, que embasam a construção de outros paradigmas, como os produzidos na Amazônia, e, nesse caso, na comunidade quilombola Benevides.

Neste trabalho, sugere-se compreender os usos, os significados e a conservação que os quilombolas da comunidade atribuem ao vegetal conhecido como Espada de São Jorge, ou Espada de Ogum, uma vez que, apesar de uma boa expressão de estudos terem sido desenvolvidos nas comunidades quilombolas do Aproaga, não existem trabalhos que contemplem a relação do botânico com o campo religioso ${ }^{3}$. A pesquisa se desenvolveu a partir de uma metodologia orientada por uma observação etnográfica na comunidade. O período foi de aproximadamente quatro meses. Neste tempo, a observação participante articulou as ações e as significações dos sujeitos que cultivam e narram a planta sagrada estudada. Os mais ouvidos foram Sr. Bonifácio e a Sra. Conceição. Sob o reconhecimento dos moradores, eles são pessoas importantes da comunidade, sobretudo por suas importâncias para a perpetuação da memória e plantio da Espada de São Jorge. A entrevistas aconteceram sob o rigor da legislação vigente, aquelas que balizam a ética na pesquisa de povos tradicionais.

\section{A COMUNIDADE QUILOMBOLA BENEVIDES}

A comunidade Benevides faz parte de um conjunto de mobilização de remanescentes de escravos, que se denominou Povo do Aproaga, após a cartografia social traçada pelo Projeto Nova Cartografia Social da Amazônia, levando-se em consideração a memória social compartilhada, os recursos de usos coletivos e a representação política, cuja expressão se deu com a AQURC (MORAES, 2012).

Benevides, está localizada às margens do rio Capim, e é cortada pela Rodovia PA-272, no município de Aurora do Pará, distando da cidade a 26 km, e de Belém, a aproximadamente 220 km, enquadrando-se geograficamente no nordeste paraense, possui aproximadamente 25 famílias, que desenvolvem a agricultura sustentável, a extração do açaí, da castanha do Pará, e cultivam as tradições dos seus antepassados, quando lá chegaram na condição de escravizados.

\footnotetext{
${ }^{3}$ Para esclarecer o conceito de "lugar sagrado", recorremos a uma definição elaborada por Pierre Boudireu: “é um espaço no qual agentes que é preciso definir (padre, profeta, feiticeiro, etc.) lutam pela imposição legítima não só do religioso, mas também das diferentes maneiras de desempenhar o papel religioso" (BOURDIEU, 2004).
} 
A comunidade está ligada à Vila de Santana do Capim (um dos povoados fundados no século XIX), através de uma ponte de 1.300 m, sobre o rio Capim, construída por meio do PAC II, do governo federal. A área mais povoada de Benevides fica à direita da ponte, enquanto que a menos povoada se liga através de uma vicinal, que ladeia a vegetação, inclusive, os castanhais. Esse lugar de mata é tido como um lugar sagrado, onde os encantes/orixás aparecem aos humanos, segundo afirmou Sr. Bonifácio, um dos interlocutores da pesquisa. Para o Senhor Bonifácio, os encantandos/orixás que "baixam” no seu terreiro, são aqueles que frequentam os territórios da mata, estradas e o rio Capim; são aqueles que se corporificam e aparecem às pessoas que transitam pelas vicinais, que ficam na mata ou no rio, enfim, àqueles que transitam nos horários “impróprios” e são estranhos à comunidade local. O Sr. José Bonifácio (já citado) e a Sra. Maria da Conceição autorizaram seus nomes próprios e suas narrativas para esta pesquisa. É importante destacar que na comunidade Benevides há outras pessoas que também possuem o "fado” de utilizarem as bênçãos para curas.

O manejo dos recursos naturais pela comunidade é o resultado de saberes que não são destinados apenas às necessidades biológicas dos remanescentes, mas, a um conjunto de conhecimentos que regula o modo de ser e de viver da população, margeados de sentidos simbólicos. Esses conhecimentos são ordenados como estratégias capazes de atender às necessidades socioculturais no que diz respeito a plantar suas roças, coletar amêndoas, caçar, pescar, comercializar e preservar o meio ambiente. Nessas práticas quotidianas, verificam-se as relações sociais a partir da mobilização familiar nas tarefas da agricultura, principalmente, no cultivo de mandioca, uma das maiores fontes econômicas da comunidade.

É no "plantio do roçado" que desenvolvem os plantios de maniva, feijão, verduras e frutas, sendo estes plantados dentro de um calendário que faz parte de seus códigos culturais e que considera as estações do ano como base para o preparo da terra - desde a queima no período de verão ou “estiagem” ao plantio, que acontece, geralmente, no início das chuvas. No âmbito da produção econômica, há a farinha de mandioca como o produto de relevância maior, uma vez que essa atividade agrícola acontece constantemente nas roças da comunidade. As demais atividades obedecem a um calendário de safra, que, por sua vez, é cíclico.

Vale ressaltar a respeito da existência de benzedores e curadores na região. Ao mesmo tempo em que participam dos rituais católicos, eles/elas benzem e rezam em "mau-olhado", 
“quebrantos” e “flechadas”, ocasionadas por pessoas que possuem "energias negativas” ou seres que se encontram encantados nas águas dos igarapés e no rio Capim.

O uso de plantas sagradas é utilizado pelos remanescentes da região. Essas plantas são cultivadas na mata de igapós, de terra firmes, roças e quintais pelos remanescentes de quilombolas em tela, para efetuar a cura de “patologias” citadas. Esses vegetais foram herdados dos seus antepassados; assim, seus usos, significados e conservação foram aprendidos e transmitidos através da memória das gerações, em harmonia com a natureza, e articulam seus modos de vida com os recursos naturais, desenvolvendo uma cultura de vasto conhecimento dos mesmos. Segundo Diegues (1999, p. 14-15),

essas populações desenvolvem modos de vida particulares que envolvem uma grande dependência dos ciclos naturais, um conhecimento profundo dos ciclos biológicos e dos recursos naturais, tecnologias patrimoniais, simbologias, mitos e até uma linguagem específica.

Dessa forma, o autor sugere que as populações tradicionais contribuem para o aumento da diversidade de espécies, de conhecimentos dos ecossistemas e da genética, uma vez que desenvolveram uma relação de simbiose com a natureza e, consequentemente, uma relação de manipulação dos recursos naturais sem causar danos aos ecossistemas com os quais se relacionam. Assim, é possível notar que a biodiversidade não se restringe a processos meramente naturais, mas, que existe uma relação cultural nestes, o que caracteriza a biodiversidade, daí a existência do sagrado, do numinoso ${ }^{4}$.

Neste texto, busca-se uma compreensão dos usos, significados e conservação, através do cultivo do vegetal conhecido na comunidade por Espada de São Jorge, ou Espada de Ogum, utilizando o exercício hermenêutico, na perspectiva de compreendermos as narrativas dos interlocutores que moram na comunidade: Sr. Bonifácio e Sra. Conceição. Ambos utilizam a planta Espada de São Jorge nos seus afazeres medicinais, enquanto cura física ou espiritual. O primeiro identifica-se como Pai de Santo - que segundo, Roger Bastide, é uma tipologia sacerdotal oriunda das religiões afro-brasileiras (BATISDE, 2001). A segunda já se identifica como Benzendeira - atora religiosa que, para Elda Oliveira, pratica a cura de males

\footnotetext{
${ }^{4} \mathrm{O}$ conceito de numinoso foi adotado por Rudolf Otto em sua obra O sagrado (OTTO, 2007) no qual o pensador revela as dimensões originárias da religião. Esta dimensão originária emerge de experiências intimas dos humanos com a dimensão mais totalizante da vida, com àquilo a partir do qual tudo ganha sentido. $\mathrm{Na}$ Comunidade quilombola Benevides, as pessoas entrevistadas possuem qualidades transcendentes com o sagrado. Na comunidade este fenômeno é conhecido por "fado".
} 
culturais associando quase sempre ervas curadas a rezas quase sempre católicas (OLIVEIRA, 1985).

\section{USOS, SIGNIFICADOS E CONSERVAÇÃO DA PLANTA ESPADA DE SÃO JORGE SOB O PRISMA HERMENÊUTICO}

Inspirados em Grondim (2002), a compreensão do pensamento hermenêutico é estruturada basicamente por três eixos: a arte de interpretar textos; uma reflexão metodológica sobre a pretensão de verdade e o estatuto científico das ciências humanas; e a filosofia universal da interpretação. Neste trabalho, buscamos a filosofia de Paul Ricoeur (1913-2005) para compreendermos a simbologia que a planta apresenta, bem como as narrativas dos interlocutores da pesquisa.

Seguindo as orientações de Camargo (2014) a Espada de São Jorge, Sansevieria zeylanica, também conhecida como Espada de Ogum, é um vegetal originário do continente africano, introduzido no Brasil com propósitos religiosos e legitimado dentro das casas de culto afro-brasileiras. Além de aspectos rituais, a Espada de São Jorge é utilizada para outros fins, como, ornamentação de jardins, casas, tratamento fitossanitários etc. Vale salientar que, neste trabalho, enfatiza-se o aspecto religioso, no sentido de compreender a utilização da $S$. zeylanica na comunidade quilombola em estudo.

Para Nascimento (2003) o gênero botânico Sansevieria é constituída de, aproximadamente, sessenta espécies. Em aspectos gerais, Sansevieria se caracteriza por uma forma entouceirada e atinge altura entre 30 e $70 \mathrm{~cm}$. Suas folhas são dispostas verticalmente, laminares, lanceoladas, de cor verde-escura, com bandas transversais (LORENZI \& MELLO FILHO, 2001). Na taxonomia da Sansevieria, a Espada de São Jorge seria a espécie zeylanica. Ela é a que mais está presente nos rituais de cura, ornamentações e fitossanitariamente na comunidade Benevides.

No Brasil, apesar das demais utilizações da Espada de São Jorge, o uso dessa planta é mais observado para efeito sagrado, como proteção do corpo e do espírito pelas pessoas, ou para evitar o “olho gordo” e a “inveja”. Nos terreiros afro-brasileiros, a estética morfológica da planta remete a uma espada, daí ser conhecida popularmente como Espada de Ogum ${ }^{5}$, que é sincretizado com São Jorge, santo católico. Segundo as narrativas populares, este nasceu na

\footnotetext{
${ }^{5}$ Em ioruba, significa luta, guerra, arma; É a divindade dona das armas, senhor dos exércitos, protetor dos caminhos. Forja o ferro e o transforma em instrumento de luta; Na África, Ogum de muita popularidade. É a representação do escravo reprimido, apartado e isolado de sua terra (ROCHA, 2001).
} 
Capadócia; ainda criança, ficou órfão de pai e sua mãe o levou para a Palestina, tornando-se militar na corte do imperador Diocleciano e se insurgindo contra aquele rei na ocasião em que planejava matar os cristãos. Após tentativas sem sucesso para que o militar renunciasse à sua fé, o imperador mandou degolá-lo no dia 23 de abril do ano 303 d.C. É esse santo católico que nomina popularmente a planta estudada na comunidade Benevides.

No decorrer de nossa pesquisa na comunidade, observamos que a planta é cultivada dentro de vasos ou sobre o solo, dentro das casas, bares e roçados. Nos bares, as plantas são cultivadas consorciadas com outras espécies, tidas como protetoras. Dentre elas, pinhão rôxo (Jatropha gossypiifolia), comigo-ninguém-pode (Dieffenbachia picta) e o cipó d'alho (Mansoa alliacea). Nos roçados, a Espada de São Jorge é cultivada nos aceiros dos mesmos, plantada em touceiras, nos quatro cantos da área ocupada, bem como em fileiras para separar um plantio de outro. No roçado observado, a planta era utilizada para separar o plantio de batata-doce de outras plantações.

No bar de dona Conceição, o uso, a conservação e os significados da planta Espada de São Jorge se dão da seguinte maneira:

Olhe, a Espada de São Jorge é uma planta muito importante pra gente ter em casa.
Ela espanta tudo que num presta na casa da gente. Minha família sempre a usou
como uma planta que serve pra tudo. Olhe, ela serve pra não deixar que outras
pessoas coloco aquele olho de má vontade nas coisas da gente. Sabe o que é, né,
gente invejosa? Gente invejosa é aquele tipo de pessoa que num tem nada, e num
qué que ninguém tenha nada... E eu pranto minhas prantinha de todo tipo delas, né?
Mas, a Espada de São Jorge, ela tem que ter, em todos os cantos da casa da gente.
Aqui no meu bar, tem, no bar da minha irmã também prantei lá, né? Pra proteger a
gente nas nossas venda. Tem gente de mau olhado, tem gente que ver uma coisa e se
for pranta, seca, né? O sinhô já viu? Pois é. Se numa pranta é assim... magine na
venda da gente, que a gente trabaia... Aqui no bar, eu pranto ela como o sinhô tá
vendo, tá aqui, pertim de mim. Só que eu misturo no vaso, a Espada de São Jorge, o
pinhão rôxo, o comigo ninguém-pode, e o cipó d'alho, e aí tá feito a nossa proteção.
Eu também faço banho pras pessoas que vem a minha procura, rezo nelas, e as vez o
que elas têm... mau olhado! Tem viu? E eu uso aqui. Aprendi essas coisas com o
povo do meu passado... que moravo aqui, né, nossos parentes que moram nas
redondezas (risos). Mas o sinhô sabia, que isso até afasta coisa ruim de perto da
gente... afasta até cobra, das cobras passo é longe da Espada de São Jorge, isso
porque o santo brigou com um dragão... da família das serpentes (Maria da
Conceição, relato concedido em 23 jul. 2019).

A narradora expressa a importância da planta Espada de São Jorge, a tradição do seu uso, memórias de ação e significação bem ancestral. Ela apresenta o sentido do uso, enquanto um elemento de proteção contra a inveja, elemento sobrenatural, cujo efeito acontece através 
do olhar de determinadas pessoas aos bens pessoais. Segundo ela própria: “Gente invejosa é aquele tipo de pessoa que num tem nada, e num qué que ninguém tenha nada...”

Também está presente a conservação da planta, que acontece consorciada com outras plantas, sagradas na região. A narradora faz relação do uso da planta ao sobrenatural; também relaciona a utilização da mesma como repelente contra cobras, ao mesmo tempo em que relaciona a religiosidade católica com a religiosidade afro-brasileira e pajelança cabocla, utilizando o símbolo, enquanto elemento de estudo da hermenêutica ricoeuriana, que se preocupa com o tempo narrado e a ação da narrativa no tempo.

Inspirado em Ricoeur, sobetudo a partir de sua obra Simbólica do Mal (2013), pensouse a Espada de São Jorge a partir de sua dimensão simbólica exercida nas narrativas e nos espaços locais. O ente botânico Espada de São Jorge tem tecido significadamente em si uma experiência reflexiva de mundo. Ou seja, a planta passa a ter um poder de presencialidade reflexiva de todo o mundo religioso que contorna a cultura na qual está inserida No contexto da comunidade quilombola Benevides, a Espada de São Jorge é a presença reflexiva da segurança na luta entre o bem e o mal, mais especificamente, na luta contra os males nomeados culturalmente como "mal-olhado" e “inveja”.

A “inveja” é uma expressão do mal na comunidade Benevides. Ou seja, é a imersão dos sujeitos numa subtração humana; mas, também faz parte das suas experiências com o sagrado. Como o mal não tem uma explicação para a filosofia, há uma recorrência ao mito para suas explicações. Dessa forma, sendo o mal e o sagrado antagônicos, o sagrado abre os caminhos para a experiência humana, e essa recorrência ao sagrado é a busca da purificação, que se encontra presente na narrativa do Sr. Bonifácio:

Uma pessoa com mau-olhado fica mofina, dá febre, nada dá certo... sabe? Tudo que ela possui fica ruim, o roçado pega fogo, roubam suas coisas, seus pertences, morre xerimbabos do quintal, às vezes até o casamento se desfaz... Tudo isso por causa do olho gordo, da inveja... da maldade das pessoas... Olho gordo é o pior de todos os feitiços, o sinhô sabia?... Eu faço trabalhos pra muitas gentes, eu já curei muitas coisas fêa... que as pessoas vêm aqui, atrás de remédio, eu tiro quase tudo que precisa do meu quintal. eu aconselho no meu terreiro para usarem as proteções e recomendo muito para usarem as ervas que protegem a pessoa. A Espada de São Jorge é a mais recomendada, porque é a proteção do meu pai Ogum. Aqui no rio, eu recebo as correntes da água e do céu... Pai Ogum, que é São Jorge, tá sempre protegendo e curando as pessoas que me procura... o terreiro dele, ele que é o chefe. Agora não... sabe? Tô meio adoentado, tive pressão alta e nunca mais trabalhei, mas fico vendo os sinais dos Orixás, nas águas do Capim... e no mato. O senhor tá vendo esse outro lado da estrada que só é mato e castanheiras? Desse lado aí, até lá embaixo, as pessoas sempre vê meus protetetor aparecere (risos)... O povo se assombra quando vê cavalo saindo do mato, e sumindo dentro do rio... São as 
entidades, são os encantando do céu e das água... aqui nesse lugar que o sinhô tá é o lugar de encantados, da cabôca Jarina, da Mariana e do Zé Raimundo... todas baixam aqui no meu terreiro..., e eles já me avisaro que o seu pai, rei Sabá, vai baixar aqui também... mas os mais comuns de baixá são os preto velho que vieram da África, junto dos parente que viero nos navio e chegaro pra cá... depois eles foro pra mata, pra proteger a gente e o garapé, viero com os seus filhos, que se tornaro escravo. O senhor sabe a história daqui? Tudo aqui era escravo... Tudo foi passando de pai pra filho, e eu herdei o dom de receber os orixá, e só fui ser pai de Santo, quando fui iniciado por um pai de Santo lá de Belém, que já morreu... (José Bonifácio, relato concedido em 24 jul. 2019).

O narrador se expressa relatando os efeitos do mal que são obviamente negativos, quer no plano físico ou no plano psicológico, de adoecimento, perda de bens materiais, de trabalho, e a separação conjugal, ou seja, a experiência do mal. Posteriormente, o narrador fala do mal em si, e prova sua experiência quando explica ao pesquisador sobre ele (o mal). No entanto, busca o sentido do sagrado, que está expresso nas palavras do narrador: “já curei muntas coisas fêa [...]. Eu aconselho no meu terreiro para usarem as proteção e recomendo muito para usarem as ervas que protegem a pessoa [...] A Espada de São Jorge é a mais recomendada, porque é a proteção do meu pai Ogum”.

Na narrativa do Sr. Bonifácio, a imaginação poética encontra-se expressa quando o mesmo afirma receber correntes do céu e do rio Capim, e a capacidade criadora de falar das entidades que “descem” no seu terreiro, bem como construir um território dos seres encantados, que trabalham em prol da proteção dos sujeitos da comunidade. Ao falar desses protetores, o narrador traça relações desses territórios, que fazem analogias a outros textos, ou seja, busca reduzir os textos num só, como no caso dos encantados dos lençóis maranhenses onde figuram entidades das religiosidades afro-brasileiras, como Jarina, Mariana, Zé Raimundo e Rei Sabá, a família encantada do atlântico maranhense -, concretizando, dessa forma, um jogo de linguagens e de sensibilidade que o narrador faz ao criar seu texto, sendo que é na linguagem que o cosmos, o desejo, o imaginário tem acesso à expressão; é sempre preciso uma palavra para recuperar o mundo e fazer com que ele se torne um espaço sagradamente ordenado.

Nessa perspectiva, as formas de uso e a percepção dos sentidos que a planta Espada de São Jorge propicia são frutos de textos construídos e reconstruídos cotidianamente na comunidade Benevides; formam uma hermenêutica capaz de construir sentidos a uma possibilidade do bem viver, de uma esperança que faz parte dessa trajetória do imaginário quilombola ao lidar com a mesma (planta), que se desenha na polissemia dos sentidos e a cura é, em si, elemento da ação humana naquela comunidade. 
A cura é o resultado da experiência humana com o sagrado, essa "energia” que se abre para a superação, ou seja, para a superação do mal, da inveja, do "olho gordo", experimentados através dos seus efeitos. Dessa forma, esse cenário sempre se recorre aos símbolos do sagrado colocando os homens além da crença numa figura da esperança. Essa figura é exigida pelo sagrado para que possa ser expressa, através dos sentidos.

\section{CONSIDERAÇÕES FINAIS}

No contexto atual, em que a Amazônia vem sofrendo com a danificação de seus ecossistemas, necessários à vida de todos os seres, a reflexão acerca da dimensão que os homens lidam com seus símbolos e suas cosmologias traz à baila a necessidade de aplicar uma hermenêutica das expressões religiosas inspirada na filosofia de Paul Ricouer, enquanto fornecedores de bases para compreender a Amazônia; e, dessa forma, visibilizar os diversos textos de suas populações, inclusive os saberes ambientais e sagrados das populações quilombolas que elaboram para dar sentido às suas existências, quando o preconceito étnico os invisibiliza nas políticas públicas e estes ressignificam suas religiosidades, seus territórios, seus hábitos e costumes, criando e recriando seus símbolos, com suporte nos sistemas culturais e sagrados. Estas têm sido as âncoras de resistência dos povos quilombolas em Benevides. Dessa forma, cria-se a expectativa no avanço da hermenêutica noutros trabalhos, afim de permear os campos impermeáveis da ciência cartesiana.

A Espada de São Jorge, além de planta, é um símbolo que aguça o pensamento a partir das problemáticas desafiadoras do século XXI. Isso porque ela resiste às condições climáticas elevadas, consegue purificar biologicamente o ambiente e purificar as "manchas do mal” que afetam o espírito humano, na cosmologia quilombola. A Espada de São Jorge é uma expressão de defesa e resistência. É uma força pela sobrevivência sustentada pela cultura quilombola.

\section{REFERÊNCIAS}

ASSOCIAÇÃO QUILOMBOLAS UNIDOS DO RIO CAPIM. Povos do Aproaga, São Domingos do Capim, Pará. Belém, PA: AQURC; Ed. UFAM, 2008. (Projeto Nova Cartografia Social da Amazônia. Série Movimentos sociais, identidade coletiva e conflitos, 24). Disponível em: http://novacartogra fiasocial.com.br/download/24-povos-do-aproaga-saodomingos-do-capim-pa/. Acesso em: 3 jun. 2020.

BASTIDE, ROGER - O Candomblé na Bahia: rito nagô. SP Companhia das Letras, 2001. 
BORDIEU, Pierre. Gênese e estrutura do Campo Religioso. In Bourdieu, Pierre. Sérgio Micelli (org.). 5a. Ed. Ed. Perspectiva, São Paulo, 2004 a.

BORGES, Adão Souza. Narrativas de remanescentes de Quilombo: divergências e convergências na construção da identidade negra no Engenho do Calixto, em Aurora (PA). 2014. Dissertação (Mestrado) - Programa de Pós-Graduação em Linguagens e Saberes na Amazônia, Universidade Federal do Pará, Belém, PA, 2014.

CAMARGO, Maria Thereza Lemos de. As plantas Medicinais e o Sagrado: a Etnofarmacobotânica em uma revisão historiográfica da medicina popular no Brasil. São Paulo: Ícone, 2014.

DIEGUES, Antônio Carlos S. A construção de uma nova ciência da conservação para as áreas protegidas dos trópicos: a etnoconservação. Revista Debates Socioambientais, v. 5, n. 13, p. 9-11, jul./out. 1999.

DURKHEIM, E. Les formes elementaires de la vie religieuse. Paris: Presses Universitaires de France, 1968.

GRONDIN, Jean. Hermenêutica. São Paulo: Parábola, 2006.

LORENZI, Harri; MELLO FILHO, Luiz Emygdio de. As plantas tropicais de Burle Marx. São Paulo: Instituto Plantarum de Estudos da Flora, 2001.

MORAES, Irislane Pereira de. Do tempo dos pretos d'antes aos povos do Aproaga: patrimônio arqueológico e territorialidade quilombola no vale do rio Capim (PA). 2012. Dissertação (Mestrado) - Programa de Pós-Graduação em Antropologia, Instituto de Filosofia e Ciências Humanas, Universidade Federal do Pará, Belém, PA 2012.

NASCIMENTO, Ticianny Melo do; GRAZIANO, Taís Tostes; LOPES, Camila Schultz. Espécies e cultivares de sanseviéria como plantas ornamentais. Ornamental Horticulture, Campinas, v. 9, n. 2, 2003.

OLIVEIRA, Elda Rizzo. O que é benzeção (coleção Primeiros Passos). São Paulo, 1985.

OTTO, Rudolf. O sagrado: aspectos irracionais na noção do divino e sua relação com o racional. Tradução de Walter O. Schlupp. São Leopoldo: Sinodal, EST; Petrópolis: Vozes, 2007.

RICOEUR, Paul. A simbólica do mal. Lisboa: Edições 70, 2013.

ROCHA, Marlúcia Mendes da. Ogum. Revista KÀWÉ, n. 2, p. 14-16, 2001. Disponível em: http://www.uesc.br/nucleos/kawe/revistas/Ed_02/ogum.pdf. Acesso em: 3 jun. 2020.

SIQUEIRA, Deis Elucy. Biodiversidade, Estado brasileiro e religião na Amazônia. HORIZONTE - Revista de Estudos de Teologia e Ciências da Religião, Belo Horizonte, v. 8,
n.
17 ,
p. 56-78,
abr./jun.
2010.
Disponível
em: 
http://periodicos.pucminas.br/index.php/horizonte/article/view/1772/0. Acesso em: 2 jun. 2020. 